\title{
Multiple magmatic reactivations in volcanic ridges and its geotectonic implications: Brazilian Equatorial Margin
}

Marcos Vinícius Moraes dos Santos ${ }^{1}$, Antônio Tadeu dos Reis ${ }^{1}$, Cleverson Guizan Silva ${ }^{2}$

${ }^{1}$ School of Oceanography, Universidade do Estado do Rio de Janeiro, Rio de Janeiro, RJ, Brazil

2 Department of Geology and Geophysics, Universidade Federal Fluminense, Niterói, RJ, Brazil

Copyright 2021, SBGf - Sociedade Brasileira de Geofísica.

This paper was prepared for presentation during the $17^{\text {th }}$ International Congress of the Brazilian Geophysical Society held in Rio de Janeiro, Brazil, $16-19$ August 2021.

Contents of this paper were reviewed by the Technical Committee of the $17^{\text {th }}$ International Congress of the Brazilian Geophysical Society and do not necessarily represent any position of the SBGf, its officers or members. Electronic reproduction or storage of any part of this paper for commercial purposes without the written consent of the Brazilian Geophysical Society is prohibited.

The Brazilian Equatorial Margin, is characterized by the presence of prominent seamounts which align themselves in the E-W or NW-SE directions, constituting the North Brazilian Ridge (NBR) and the Fernando de Noronha Ridge (FNR).

There are many hypotheses about the origin of these volcanic ridges: Magmatism generated by lateral lithospherical movementation with consequent depressurization and partial mantle melt (caused by a change of pole of rotation, Le Pichon and Hayes, 1971 for NBR, or due lithospheric accommodation in fracture zones, according to Almeida, 1956, for the FNR); Magmatism generated by vertical lithospherical movementation (caused by flexure of the lithosphere, as a result by anomalous sedimentary concentration, in the NBR region, according to Gorini, 1977); or magmatism generated by the influence of a mantle plume (of NW-SE direction origininating the Ceará Rise, NBR and FNR, according to O'Connor \& Duncan, 1990, or of E-W direction, being responsible for the formation of FNR).

This abstract aims to debate new evidence about the discussion of this magmatism on Brazilian Equatorial Margin, based on the analysis of seismic data, acquired and provided by LEPLAC project (Plano de Levantamento da Plataforma Continental Brasileira). The results obtained by this work reinforce the hypothesis of a mantle plume as a common probable cause of the magmatism of the NBR and FNR.

\section{Results and Conclusion}

The analysis of seismic data from the Brazilian Equatorial margin made it possible to identify several seismic features with typical characteristics of volcanic bodies, associated laterally to seamount and submarine ridges. These bodies occur isolated along the stratigraphic column, or in up to three bodies separated by a sedimentary sequence, denoting possible events of magmatic reactivations. Through the correlation to chronostratigraphic horizons, was identified a gradation of the ages associated to the bodies, estimated to be older than 66.0 Ma the west portion of the NBR (northern segment) becoming more recent (younger than 2 $\mathrm{Ma}$ ) as it approaches the easternmost portion of the FNR. This fact leads us to believe in an origin/evolution common to both submarine ridges at an approximate rate of $22.1 \mathrm{~km} / \mathrm{Ma}$, which is compatible with the usually estimated for propagation of a mantle plume.

This indications in association with other factor, such as: the projection of the São Paulo, Romanche and Chain Fracture Zones (with the northern and southern segment of the NBR and with the FNR, respectively) and the oceanic nature of the crust in both portions of the ridges, lead us to believe that the most probable hypothesis for this magmatism creation is the interaction between Fernando de Noronha's mantle plume and the South American plate. This magmatism possibly took advantage of pre-existing structures: fracture zones and a ridgejump (in central segment of the CNB), deep listospheric structures. 